\title{
Preparative supercritical fluid chromatography
}

\author{
P. Jusforgues and M. Shaimi
}

Prochrom S.A., 5 rue Jacques Monod, BP. 9, 54250 Champigneulles, France

\begin{abstract}
Preparative Supercritical Fluid Chromatography (Prep-SFC) is presented here as it appeared historically: that is to say as the application of the supercritical fluids (SF) interesting properties to Preparative HPLC process. The advantages induced by the use of SF instead of liquid solvents are both practical and economical: the low solvent consumption of Prep-SFC avoids the storage of large quantities of solvent and considerably reduces the upstream and downstream processing costs of the solvent. The drawbacks of SF are both practical and economical too: SF processes are high pressure ones and, subsequently, investments costs are higher than HPLC's ones. Application examples illustrate the development of a separation method. Finally the main features of Prep-SFC economics are given to define more precisely the place of Prep-SFC as a complementary technique of Preparative HPLC.
\end{abstract}

\section{Introduction}

Historically, Preparative Supercritical Fluid Chromatography (Prep-SFC) was invented by KLESPER et al. [1] since, in their first report on analytical SFC, they mentioned the possibility to collect the separated compounds. Analytical SFC was developped by pionneers in their laboratory during the 60's and 70's. Prep-SFC really started to be studied and developped after Perrut patented the large scale Prep-SFC with eluent recycling [2]. In the 90's, commercial equipment appeared [3] and applications are developped for industrial purpose. A bibliographic basis of Prep-SFC works can be found in references [4-14].

\section{SF for chromatography}

Prep-SFC can be described as the application of Supercritical Fluids (SF) properties to Prep-HPLC.

Supercritical Fluids (SF) are more and more widely used in industry and their field of applications is increasing every year: extraction, material processing (dyeing, coating, impregnation, particle generation), soil depollution, reaction [13].

Some properties of SF are particularly favorable to their use in Prep-SFC:

- good solvent properties (like liquids and unlike gases),

- low viscosity and high diffusion coefficients (intermediate between gases and liquids),

- easy modulation of solvent properties by pressure adjustment (possibility to transform a SF into a gas by isothermal depressurization).

The principle and characteristics of Prep-SFC can be described on a phase diagram (Fig. 1).

This is a description of the simplest Prep-SFC process which uses a pure compound as supercritical eluent (in more than $95 \%$ of the cases this pure compound is carbon dioxide).

Note that it is often necessary to add a "modifier" to carbon dioxide to enhance or modify its solvent properties. The modifier is most often a liquid solvent. A Prep-SFC process including a modifier differs from the simplest scheme and the two options will be treated here.

Like all preparative chromatographic systems, Prep-SFC processes can be classified into four scales:

- Micro-Prep-SFC is not described here: it is meant to purify micrograms or milligrams and uses a slightly modified analytical chromatograph. 


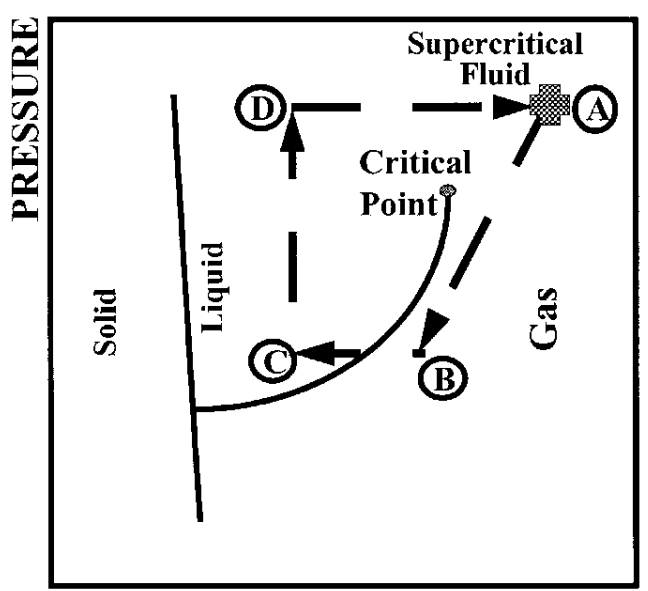

TEMPERATURE

Figure 1. Phase diagram of a pure compound. A) the eluent is supercritical in the chromatographic column; B) at column outlet, the eluent is depressurized (and heated) down to the gas phase; in the gas phase, eluent is cleaned, pure fractions precipitate and are collected; C, D) cleaned gaseous eluent can be recycled, preferentially through a condensation (C), a recompression (D) and heating to the operating temperature (A).

- Lab-Prep-SFC is used to purify hundreds of milligrams or grams. It requires a specific technology but cannot be addressed as large scale SFC.

- Pilot-Prep-SFC is used to purify kilograms per day on columns having an internal diameter between 5 and $15 \mathrm{~cm}$. It can be used for scale up studies or even for some small industrial productions.

- Production-Prep-SFC is used to purify hundreds of kilograms to tens of metric tons per year. That scale of production takes full advantage of the economical interest of Prep-SFC.

Table I gives examples of production scales obtained with different diameters of column. Of course these are only typical figures and, depending on the application case, actual figures can be twice bigger or 5 times smaller.

\section{Distinctive features of Prep-SFC}

Prep-SFC is best described by comparison with Prep-HPLC and the Simulated Moving Bed (SMB) technique.

Table I. Examples of production scales.

\begin{tabular}{lccc}
\hline $\begin{array}{l}\text { Column } \\
\text { diameter }(\mathrm{mm})\end{array}$ & \multicolumn{2}{c}{ Typical loading capacity } \\
$(\mathrm{g} / \mathrm{hr}$ & tons/year) & $\begin{array}{c}\text { Carbon dioxide flow } \\
\text { rate }(\mathrm{kg} / \mathrm{hr})\end{array}$ \\
\hline 100 & 60 & 0.5 & 100 to 200 \\
200 & 240 & 2 & 400 to 800 \\
300 & 540 & 4.5 & 900 to 1800 \\
500 & 1500 & 12.5 & 2500 to 5000 \\
\hline
\end{tabular}

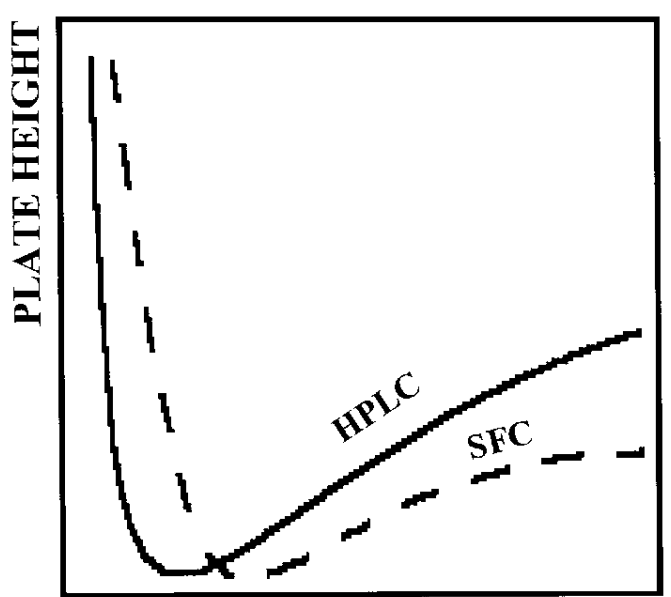

ELUENT SPEED

Figure 2. Influence of eluent speed on efficiency. Schematic comparison between HPLC and SFC.

Prep-SFC has been created to eliminate the main drawback of Prep-HPLC (i.e. the use of large quantities of expensive solvents) while maintaining its high flexibility and efficiency. Prep-SFC cuts the solvent use by a factor of 5 to 20 (if a modifier is used) or uses no solvent (if no modifier is used) but requires too a high level of investment and has a limited range of applications.

On the other hand, SMB cuts the solvent use by a factor of 1.5 to 10 but requires a higher level of investment and is limited to binary separations.

\section{Advantages}

The range of selectivities accessible by SFC is the same as HPLC's one, though, for a given application, selectivities obtained by SFC can be much higher (or lower) than HPLC's ones.

As far as efficiency is concerned, Prep-SFC compares favorably with Prep-HPLC since the same plate heights can be obtained provided the right column technology (i.e. dynamic axial compression) is applied. Moreover, Prep-SFC has the advantage of being able to combine high efficiencies with high speeds (see Fig. 2). Thanks to the much smaller diffusion coefficients of SF, the HETP versus eluent speed curve is flatter and it is possible to increase the eluent speed (and the productivity) without loosing much efficiency. Finally, thanks to the smaller viscosity of SF, the limits of the maximum allowed pressure drop across a column which sometimes limits eluent speed in HPLC doesn't exist in SFC.

Prep-SFC is a low temperature process since the practical temperature range of Prep-SFC is from $0{ }^{\circ} \mathrm{C}$ to $100{ }^{\circ} \mathrm{C}$ and most applications are made between $30^{\circ} \mathrm{C}$ and $50^{\circ} \mathrm{C}$. These moderate temperatures allow the processing of thermolabile molecules.

Prep-SFC is a flexible process and compares well to Prep-HPLC. Applications are not limited to binary separations and it is possible to selectively isolate one or several 
compounds or to remove an impurity from a complex mixture. The same equipment can be used to purify various crude batches in campaigns of production and it is possible to stop and start a system in a few hours.

Flexibility can be seen too by the easy scale up of a method developed in a laboratory by multiplying the size of the system (flow rates, injected quantity, cross section of the column, ...) by the scale factor.

Figure 3 gives an example of the scale up possibility.

When no modifier is used, Prep-SFC can be considered as a "no solvent" process: carbon dioxide is used in most cases, it is recycled on line thus there is no solvent consumption, no large storage necessity, no evaporation devices required for downstream processing, no problem with undesirable solvent traces left in the final product. As we will see, the absence of solvent is an advantage too when it comes to the economics of large scale separations.

With a modifier, Prep-SFC is an "easy solvent" process. When a modifier has to be mixed with the supercritical main eluent (carbon dioxide), some of these advantages are lost but not all of them. The modifier is added to the eluent at low levels $(0.1$ to $25 \%$, most often 1 to $5 \%)$. Thus, only a fraction of the eluent is not recycled on line which means reduced solvent storage and smaller evaporation utilities than for Prep-HPLC. Moreover the modifier used will very often be a single solvent (not a mixture) which simplifies its evaporation and recycling. Most often the modifier will be a lower alcohol (methanol, ethanol, isopropanol) which low toxicity is not a problem when traces are left in the final product. Finally the economical advantage over Prep-HPLC is not completely lost because of the reduced quantity of solvent and the easiness of its recycling.

\section{Limitations}

Large and/or polar compounds have a limited solubility in pure carbon dioxide. As it has been already mentioned, it is then necessary to add a modifier to the supercritical eluent to enhance the solubilities. The use of a modifier widens the range of applications of Prep-SFC and about $80 \%$ of the practical applications use modified $\mathrm{CO}_{2}$ as eluent. However, some classes of compounds are still insoluble in carbon dioxide and modifier. For example, some peptides can be

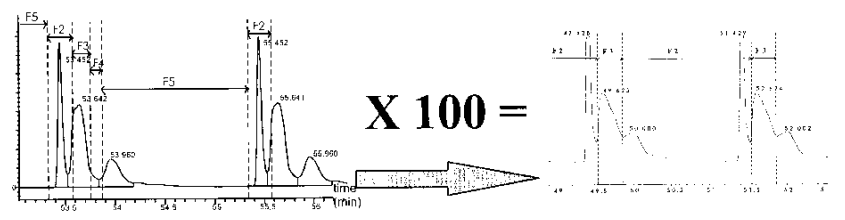

$10 \mathrm{~mm}$ ID column

$18.9 \mathrm{~g} /$ day injected $14 \mathrm{~g} /$ day collected $99.0 \%$ pure

$80 \%$ collect yield
$100 \mathrm{~mm}$ ID column $1824 \mathrm{~g} /$ day injected $1416 \mathrm{~g} /$ day collected $\mathbf{9 9 . 4} \%$ pure $84 \%$ collect yield
Figure 3. Scale up example. Purification of an insecticide. dissolved and processed by SFC but proteins are out of the range of Prep-SFC (note that, in the future, it will be possible to process proteins with a new technique called reverse micelle SFC). Statistics on the samples processed in our laboratories show that about two thirds of HPLC applications can be processed by SFC.

Another limitation of Prep-SFC is economical. Investments in Prep-SFC are much higher than in PrepHPLC. Savings on solvent consumption will counterbalance the difference on investment only for large or very large scale applications. For small or medium size applications, when both techniques are applicable, HPLC will most often be more economical than SFC.

\section{Application examples}

Prep-SFC has only been commercially available since the mid 90's thus only a limited number of applications have been published.

The most studied application is the purification of omega3 unsaturated fatty acids from fish oil extracts [5,7,12]. PrepSFC is particularly well suited for this application. Pure carbon dioxide is used as eluent and large scale productions are programmed (tens of tons per year). Economics of the process shows that separation by Prep-SFC costs 2 to 5 times less than by Prep-HPLC and the final quality of the product is better.

More recently, other applications have been patented among which one important example is the purification of cyclosporine (a cyclic undecapeptide) with carbon dioxide and a alcohol as modifier.

A special niche for SFC and Prep-SFC is the chiral separation of racemates: very good results are obtained in terms of selectivity and separation speed. Moreover, the limited solubility of the compounds to be purified is not a specific drawback of Prep-SFC: HPLC suffers from it too.

\section{Cis-trans isomers separation: phytol}

The separation of the cis and trans isomers of phytol has been chosen as an application of Prep-SFC using carbon dioxide and a modifier (isopropanol) as eluent.

Phytol is a fatty alcohol and its trans isomer is used as a fixer in perfumery. The separation has been done on a laboratory scale equipment and it has been extrapolated to industrial production. The main steps of the optimization procedure are given thereunder.

\section{Operating conditions}

A classical silica stationary phase has been retained because it was the only phase to give a selectivity between the two isomers.

It is necessary to add a modifier to carbon dioxide because pure carbon dioxide doesn't elute the sample on silica. Methanol, ethanol and isopropanol have been tested (Fig. 4). The difficulty of the separation lead us to choose IPA that gives the best selectivity.

Intermediate temperature $\left(50{ }^{\circ} \mathrm{C}\right)$ has been chosen to maintain good resolution and short cycle time. $25 \mathrm{MPa}$ and $5.5 \%(\mathrm{w} / \mathrm{w})$ of IPA in carbon dioxide have been chosen as pressure and modifier content. 


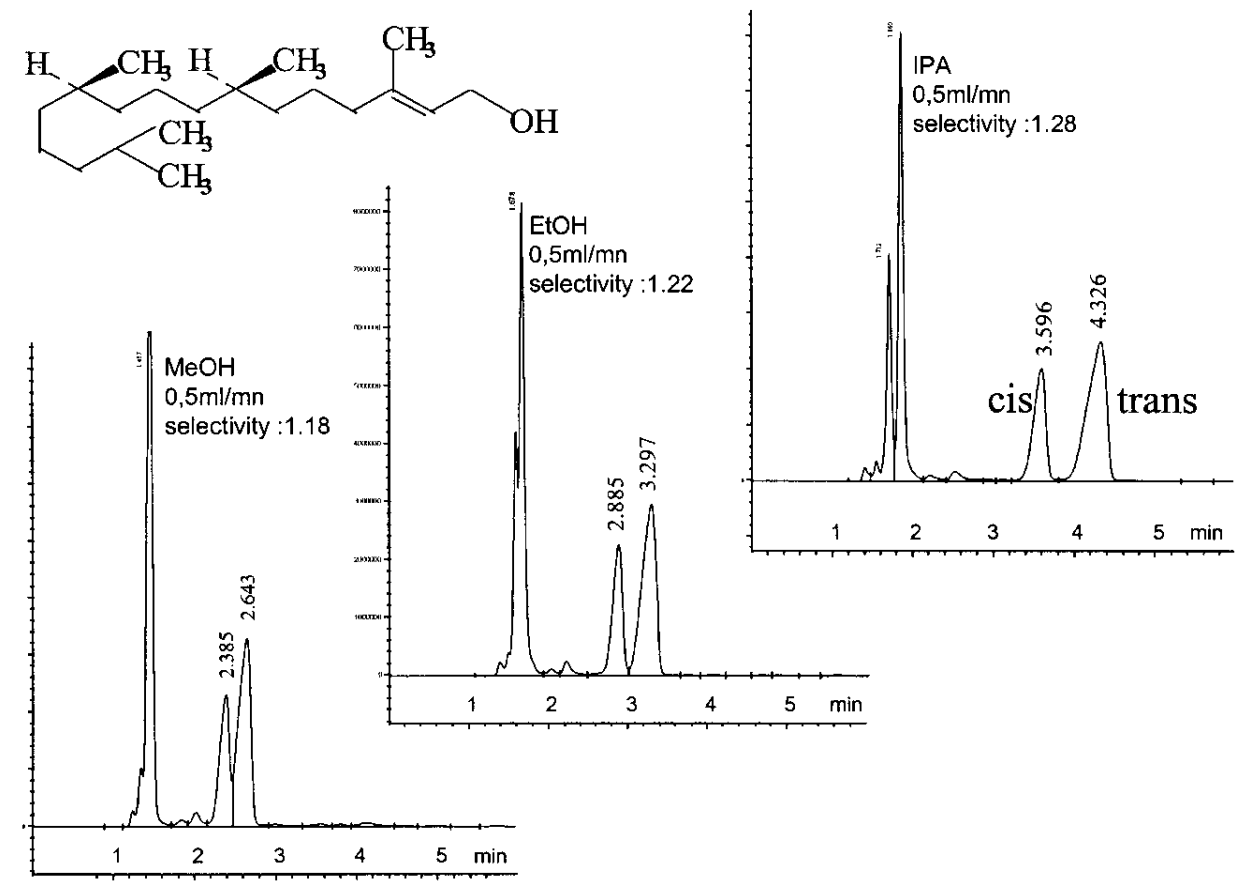

Figure 4. Phytol purification; modifier selection. Stationary phase: Silica $15 \mu \mathrm{m}, 100 \AA$ A AMICON; column: $10 \mathrm{~mm}$ ID $\times 250 \mathrm{~mm}$ L; temperature: $50^{\circ} \mathrm{C}$; pressure $25 \mathrm{MPa}$; carbon dioxide flow rate: $13.5 \mathrm{~g} / \mathrm{min}$; modifier: $\mathrm{MeOH}$, EtOH or IPA at $0.5 \mathrm{~mL} / \mathrm{min}(2.9 \% \mathrm{w} / \mathrm{w})$; sample: phytol crude: $10 \mu \mathrm{L}$.

\section{Overloading}

The thermodynamics of the separation is governed by a concave upward adsorption isotherm (low concentrations migrate faster through the column than high concentrations) even for rather small loadings $(10 \mu \mathrm{L}$ on a $10 \mathrm{~mm}$ ID column). This phenomenon can be clearly seen in figure 5 .

\section{Small scale production}

On the basis of these results, a production has been made described in figures 6 and 7 and in table II.

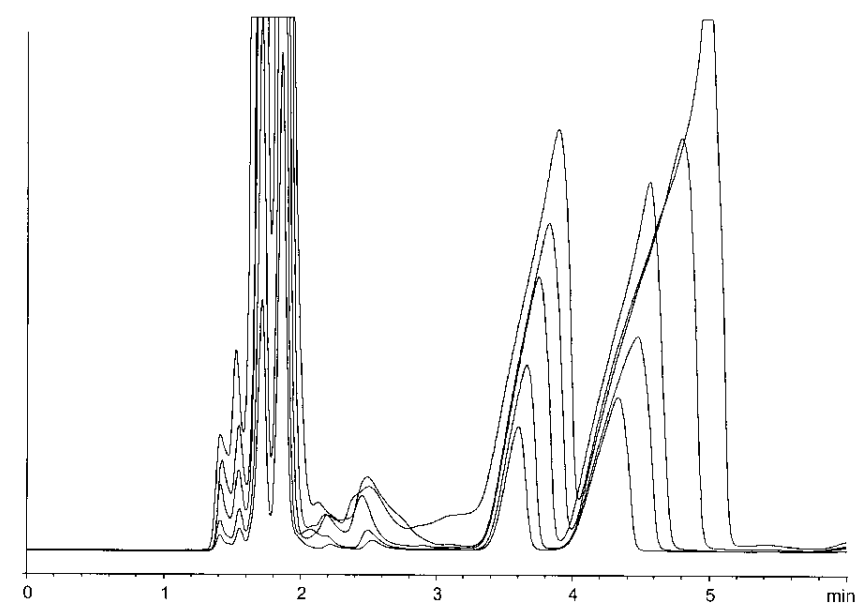

Figure 5. Phytol purification. Peaks distortion due to overloading. Modifier: IPA; sample: phytol crude: $10 \mu \mathrm{L}, 20 \mu \mathrm{L}, 40 \mu \mathrm{L}$, $60 \mu \mathrm{L}$ and $100 \mu \mathrm{L}$; other conditions as in figure 4 .

\section{Extrapolation}

Extrapolation of these results to an industrial production can be made directly and gives a production of the trans isomer of phytol on a $300 \mathrm{~mm}$ ID column of 2.3 metric tons per year (4 tons of crude injected) with a purity of $97.8 \%$ and a recovery ratio greater than $80 \%$.

\section{Economics of Prep SFC}

As in other separation processes, the economics of a separation depends a lot upon the application treated and the same Prep-SFC equipment can purify 1 kilogram per day or

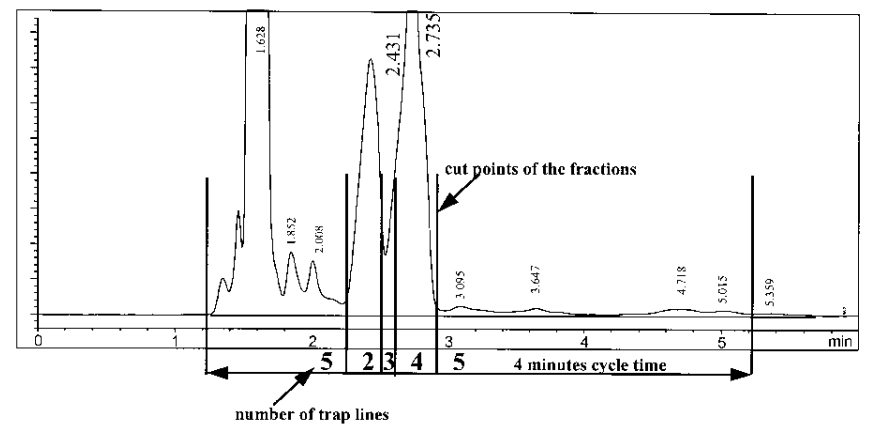

Figure 6. Chromatogram preliminary to production test. Stationary phase: Silica $15 \mu \mathrm{m}, 100 \AA ̊$, AMICON; column: $10 \mathrm{~mm}$ ID $\times 250 \mathrm{~mm} \mathrm{~L}$; temperature: $50{ }^{\circ} \mathrm{C}$; pressure $25 \mathrm{MPa}$; carbon dioxide flow rate: $13.5 \mathrm{~g} / \mathrm{min}$; modifier: IPA at $1 \mathrm{~mL} / \mathrm{min}(5.5 \%$ $\mathrm{w} / \mathrm{w})$; sample: phytol crude: $60 \mu \mathrm{L}=50.5 \mathrm{mg}$ undiluted; detection: UV absorption at $220 \mathrm{~nm}$. 
50 kilograms per day depending on the cycle time, the loadability of the column, the solubility of the sample, the selectivity between the compounds of the sample, the required purity and recovery.

However, it is possible to give the main features of the cost of a separation by Prep-SFC and a reasonable range of costs. For an industrial separation (several tons per year) using pure $\mathrm{CO}_{2}$ and no modifier, the cost range is from 20 to 200 US\$ per kilogram. In that cost the share of investment is half while the eluent cost (carbon dioxide) is negligible $(2 \%)$. The high investment share is a consequence of the high pressure and the low eluent share is a consequence of the total on line recycling of a cheap solvent.

The total purification cost range for an industrial separation using $\mathrm{CO}_{2}$ and a modifier is from 40 to 400 US\$ per kilogram. By comparison with the previous example, the investment cost is slightly higher (one more pump and bigger traps) and the recycling of the modifier represents 15 to $30 \%$ of the total purification cost.

In Prep-HPLC, the cost of the solvent losses and solvent recycling can represent $60 \%$ of the total purification cost. Since an increase in production scale is accompanied by a strong decrease of the relative costs (per kilogram of product) except for the consumables costs (solvent and stationary phase), the purification costs by Prep-SFC and PrepHPLC will decrease as presented in figure 8 . The choice between Prep-SFC and Prep-HPLC can then depend upon the scale of the purification considered. For Prep-SFC, the bigger is the better.

\section{Conclusion}

The inherent promises of Prep-SFC have not yet been fully exploited. However the experience accumulated during these last years has confirmed the initial promises and made it a reliable industrial tool.

Now, Prep-SFC can be seen as a powerful separation technique for the industry. It is meant to reach high purities for difficult separations. For many applications it can compete favorably with Prep-HPLC and SMB and it should be tried whenever HPLC or SMB are envisaged for large scale separations or when the solvent is a major problem of the process (natural products).

\section{References}

1. Klesper, E.; Corwin, A. H.; Turner, D. A. J. Org. Chem. 1962, 27, 700-701.

2. Perrut, M. Fr. Pat. 1982, 8, 209-649; Eur. Pat. 1984, 0, 099765; U.S. Pat. 1983, 4, 478-720.

3. Erickson, B. Anal. Chem. 1997 November 1, 683A-686A.

4. Berger, C.; Perrut, M. J. Chromatog. 1990, 505(1), 37-43.

5. Jusforgues, P. Ph. D. Thesis, Institut National Polytechnique de Lorraine, Nancy, France, 1988.

6. Berger, C. Ph. D. Thesis, Institut National Polytechnique de Lorraine, Nancy, France, 1989.

7. Doguet, L. Ph. D. Thesis, Institut National Polytechnique de Lorraine, Nancy, France, 1992.

8. Shaimi, M. Ph. D. Thesis, Institut National Polytechnique de Lorraine, Nancy, France, 1996.

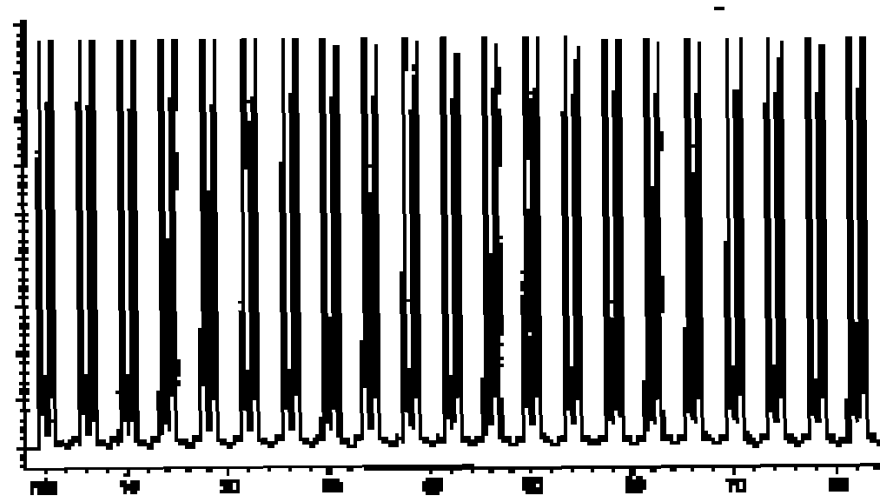

Figure 7. Phytol separation. Preparative chromatogram. Conditions as in figure 6 . One injection every 4 minutes.

Table II. Phytol separation. Preparative step results. 1 gram of crude has been injected in 1.5 hour on a $10 \mathrm{~mm}$ ID column. $95 \%$ of the injected material has been collected in four fractions. The cis and trans isomers have been collected with high purities. $68 \mathrm{~g}$ of IPA only were used for the production.

\begin{tabular}{lcccc}
\hline & Impurities & $\begin{array}{c}\text { cis } \\
\text { isomer }\end{array}$ & $\begin{array}{c}\text { trans } \\
\text { isomer }\end{array}$ & $\begin{array}{c}\text { Mass of } \\
\text { fractions }\end{array}$ \\
\hline crude & $7.6 \%$ & $34.2 \%$ & $58.2 \%$ & $1.06 \mathrm{~g}$ \\
fraction 2 & $0.2 \%$ & $99.3 \%$ & $0.5 \%$ & 0.28 \\
fraction 3 & $0 \%$ & $77.2 \%$ & $22.8 \%$ & $0.04 \mathrm{~g}$ \\
fraction 4 & $0.2 \%$ & $2 \%$ & $97.8 \%$ & $0.5 \mathrm{~g}$ \\
fraction 5 & $60.6 \%$ & $5 \%$ & $34.4 \%$ & $0.19 \mathrm{~g}$ \\
\hline
\end{tabular}

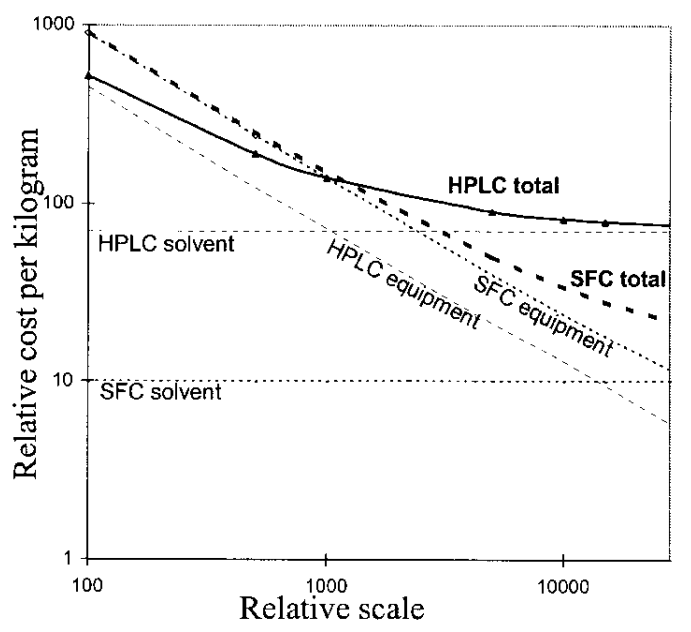

Figure 8. Dependence of the purification costs of Prep-SFC and Prep-HPLC on the scale of purification. Packing, labor and miscellaneous costs have not been included because they are similar for the two processes.

9. Yamauchi, Y.; Saito, M. Fractionation Packed-Column SFC and SFE: Principles and Applications, Saito M., Yamauchi Y., Okuyama T. Eds., VCH, New-York, 1994; p 169-178. 
10. Neffati, J. Ph. D. Thesis, Université Claude Bernard - Lyon I, Lyon, France, 1996.

11. Coleman, K.; Vérillon, F. Laboratory-Scale Preparative Chromatography Enhanced by Fluids Containing Carbon Dioxide under Automated Pressure Control, Proceedings of the 3rd International Symposium on Supercritical Fluids, Strasbourg, France, 1994; p 415-420.
12. Lembke, P. 7st International Symposium on Supercritical Fluid Chromatography and Extraction, 31 March-4 April 1996, Indianapolis, USA.

13. Proceedings of the " 5 th Meeting on supercritical Fluids", Nice, France, March 1998; ISASF, 1 rue Granville, BP. 451, F-54001 Nancy, France.

14. Jusforgues, P. Process Scale Liq. Chromatogr., Subramanian G. Ed., VCH, Weinheim (Germany), 1995; p 153-162. 